\title{
The relative contribution of climate variability and vector control coverage to changes in malaria parasite prevalence in Zambia 2006-2012
}

Adam Bennett ${ }^{1,2^{*}}$, Josh Yukich², John M. Miller ${ }^{3}$, Joseph Keating ${ }^{2}$, Hawela Moonga ${ }^{4}$, Busiku Hamainza ${ }^{4}$, Mulakwa Kamuliwo ${ }^{4}$, Ricardo Andrade-Pacheco ${ }^{1}$, Penelope Vounatsou ${ }^{5,6}$, Richard W. Steketee ${ }^{3}$ and Thomas P. Eisele ${ }^{2}$

\begin{abstract}
Background: Four malaria indicator surveys (MIS) were conducted in Zambia between 2006 and 2012 to evaluate malaria control scale-up. Nationally, coverage of insecticide-treated nets (ITNs) and indoor residual spraying (IRS) increased over this period, while parasite prevalence in children 1-59 months decreased dramatically between 2006 and 2008, but then increased from 2008 to 2010. We assessed the relative effects of vector control coverage and climate variability on malaria parasite prevalence over this period.

Methods: Nationally-representative MISs were conducted in April-June of 2006, 2008, 2010 and 2012 to collect household-level information on malaria control interventions such as IRS, ITN ownership and use, and child parasite prevalence by microscopic examination of blood smears. We fitted Bayesian geostatistical models to assess the association between IRS and ITN coverage and climate variability and malaria parasite prevalence. We created predictions of the spatial distribution of malaria prevalence at each time point and compared results of varying IRS, ITN, and climate inputs to assess their relative contributions to changes in prevalence.

Results: Nationally, the proportion of households owning an ITN increased from $37.8 \%$ in 2006 to $64.3 \%$ in 2010 and $68.1 \%$ in 2012, with substantial heterogeneity sub-nationally. The population-adjusted predicted child malaria parasite prevalence decreased from $19.6 \%$ in 2006 to $10.4 \%$ in 2008, but rose to $15.3 \%$ in 2010 and $13.5 \%$ in 2012. We estimated that the majority of this prevalence increase at the national level between 2008 and 2010 was due to climate effects on transmission, although there was substantial heterogeneity at the provincial level in the relative contribution of changing climate and ITN availability. We predict that if climate factors preceding the 2010 survey were the same as in 2008, the population-adjusted prevalence would have fallen to $9.9 \%$ nationally.

Conclusions: These results suggest that a combination of climate factors and reduced intervention coverage in parts of the country contributed to both the reduction and rebound in malaria parasite prevalence. Unusual rainfall patterns, perhaps related to moderate El Niño conditions, may have contributed to this variation. Zambia has demonstrated considerable success in scaling up vector control. This analysis highlights the importance of accounting for climate variability when using cross-sectional data for evaluation of malaria control efforts.
\end{abstract}

Keywords: Malaria, Climate, Vector control, Geostatistics

\footnotetext{
* Correspondence: bennetta@globalhealth.ucsf.edu

1 Malaria Elimination Initiative, Global Health Group, University of California,

500 16th St, San Francisco, CA 94158, USA

${ }^{2}$ Center for Applied Malaria Research and Evaluation, Tulane University

School of Public Health and Tropical Medicine, New Orleans, LA, USA

Full list of author information is available at the end of the article
} 


\section{Background}

Scale-up of vector control interventions, specifically ownership and use of insecticide-treated nets (ITNs) and indoor residual spraying (IRS), has been shown in multiple settings to reduce malaria morbidity and mortality [1-5]. Zambia made significant progress in scaling up ITN and IRS coverage from 2005 through 2012, with progress documented through repeated nationally-representative household surveys [6, 7]; over 10 million ITNs were distributed between 2005 and 2012, and roughly 850,000 structures were sprayed annually during this period. Nationally-representative Malaria Indicator Surveys (MIS) were conducted in 2006, 2008, 2010 and 2012 to monitor the progress in household coverage of ITNs and IRS at the population level, as well as to provide estimates of malaria parasite prevalence in children 1-59 months at these time-points.

Although household ownership and use of ITNs and IRS coverage as measured by these surveys increased nationally from 2006 through 2012, the proportion of children $<5$ years old with a malaria parasite infection declined from $22.4 \%$ in 2006 to $9.3 \%$ in 2008 [8], but increased somewhat to $15.9 \%$ in 2010 and $14.6 \%$ in 2012. The increase between 2008 and 2010 was variable across the country and greatest in rural areas, nearly doubling in some provinces; the proportion of children with severe anemia increased in a similar pattern with parasitemia between 2008 and 2010, from 4.3 to $9.2 \%$.

Identifying possible causes of this observed resurgence in infection prevalence between 2008 and 2010 has broad implications for malaria control programs across Africa. A historical analysis of global occurrences of malaria resurgence suggests that in most cases a flagging of malaria control effort led to an increase in incidence rates [9]. There is growing evidence of potential ITN effectiveness decay in sub-Saharan Africa (SSA) due to insecticide resistance and changes in vector biting behavior [10-12]. There is further speculation that anomalous weather patterns-perhaps related to a relatively strong El Niño episode in late 2009 and early 2010-may have influenced this resurgence in transmission, as observed elsewhere $[13,14]$.

Weather variability is a well-known driver of malaria transmission [15]. High-resolution climate and environmental data are being used with increasing sophistication in geostatistical modeling frameworks for malaria risk mapping purposes [16], where the objective is usually the production of mean endemicity surfaces [17], incidence prediction [18] or to examine changes in malaria parasite prevalence over time [19, 20]. However, until recently climate data have seldom been directly incorporated into evaluations of program impact [21-23]. Three recent examples where climate data were successfully incorporated include the evaluation of vector control scale-up and incidence data in Eritrea by Graves and colleagues
[21], work by Giardina and colleagues comparing changing parasite prevalence and vector control coverage in five countries [24], and a continental-scale evaluation by Bhatt and colleagues [5]. In order to obtain unbiased estimates of the impact of malaria control in program evaluations and assess any potential change in their effectiveness over time, analyses must directly incorporate changes in climate that influence malaria transmission potential.

Zambia reported increases in malaria parasite prevalence and health system reported clinical incidence between 2008 and 2010 that continued in 2012, despite continued scaleup of malaria control interventions during this time. This paper assessed the association between inter-annual climatic and other environmental variables, IRS and ITN coverage, and changes in malaria parasite prevalence between 2006, 2008, 2010 and 2012 while accounting for confounding factors at the subnational level. We used geostatistical models to estimate the relative contribution of subnational changes in IRS and ITN coverage and climate to changes in malaria parasite prevalence over this period.

\section{Methods \\ Malaria indicator surveys}

We used data from three Malaria Indicator Surveys (MISs), each of which was conducted at the end of the high transmission season between April and June in 2006, 2008, 2010 and 2012. The sampling design and questionnaire for these surveys has been described elsewhere [25]. Briefly, the sample size and standard enumeration areas (SEAs) were selected to provide precise estimates of ITN coverage at the national, provincial, and urban/rural levels. At the time of the surveys, there were 9 provinces and 72 districts in Zambia. While a new province was demarcated in 2011, we maintained the original 9 provinces for consistency in this analysis. A two-stage sampling design was used, with the primary sampling units consisting of standard enumeration areas (SEAs) selected proportional to the estimated population size (PPS) of each within provincial and urban/rural strata. Within each selected SEA, field workers conducted a complete household enumeration using personalizeddigital assistants (PDAs) equipped with GPS, and selected 25 households for questionnaire administration to the household head and caregivers of children under 5 years of age. Latitude and longitude were collected for each household. For SEA-level geographic information, we determined the centroid for each SEA by averaging household latitudes and longitudes.

\section{Primary outcome}

Malaria parasite prevalence in children 1-59 months served as the primary outcome. Malaria parasite prevalence was ascertained from infection status by quality controlled slide microscopy for all children 1-59 months in selected households during each MIS; HRP2 rapid 
diagnostic tests (RDTs) (ICT Malaria Pf) were used in the field to provide point of care diagnosis and treatment for children testing positive.

\section{Measures of explanatory variables and potential confounding factors}

Publicly-available remote-sensing climate data referenced to the centroid of each selected survey SEA were compiled from the following sources: the African Data Dissemination Service for 10-day rainfall estimates at $8 \mathrm{~km}$ resolution [26], the USGS Hydro $1 \mathrm{k}$ dataset for elevation at $1 \mathrm{~km}$ resolution [27], the MODIS satellite data repository for 16-day enhanced vegetation index (EVI) at $1 \mathrm{~km}$ resolution [28], the monthly Temperature Suitability Index (TSI) from the Malaria Atlas Project (MAP) [29], and Worldpop for population estimates at $1 \mathrm{~km}$ resolution [30]. We also investigated program administrative shape-files (.shp) for road networks, health facilities, and water bodies. Time-variant climate and environmental data (rainfall, TSI, and EVI) were extracted for the four months preceding the start of each survey at $1 \mathrm{~km}$ resolution.

In each MIS, a net roster was used to count the number of mosquito nets present in each selected household, including when the net was procured and who in the household slept under the net the previous night. If and when IRS was conducted was ascertained based on the recall of the head of household during each MIS. We defined a mosquito net as an ITN if it was a long-lasting insecticide-treated net (LLIN), or any net that had been insecticide treated within the past 12 months [31]. Both household and community-level ITN ownership were considered: for community-level coverage, we calculated the ITN density (number of ITNs per household members) for each SEA. We defined IRS as the survey respondent reporting that household walls were sprayed within the 12 months preceding the survey date. Similarly, we calculated the proportion of households having received IRS per SEA as a measure of community-level coverage.

As a measure of household socioeconomic status, principle-components analysis (PCA) was used to create a wealth index from a list of household assets captured during each survey [32]; this asset list did not include any household vector control items. Population density was calculated from the Worldpop raster and used as a measure of urbanness. We classified areas with $<1,000$ population per $\mathrm{km}^{2}$ as rural areas and areas with $>1,000$ population per $\mathrm{km}^{2}$ as urban/peri-urban areas. This has been shown to be a reliable cut-off for stratifying malaria risk [33]. We also calculated the Euclidean distance from each household to the nearest water body, including permanent lakes and major rivers.

\section{Variable selection and statistical analysis}

Descriptive comparisons of household vector control and parasite prevalence were conducted across surveys both nationally and by province, using survey-weighted point estimates.

\section{Climate variables}

For modeling and predicting parasite prevalence using time-varying climatic data, we considered both biological plausibility and statistical fit to select climatic variables based on lag periods preceding household data collection. For EVI, lags up to the beginning of survey data collection were considered as this index represents the effect of cumulative rainfall and humidity [further details of the selection of climate variables are presented in Additional file 1]. The best-fitting lags within biologically plausible time frames included in final models were the 20-day period of rainfall ending 6 weeks prior to the start of data collection, and the 16-day EVI in the week preceding the start of survey data collection.

\section{Model selection}

Bivariate and multivariable associations between the outcome of parasite infection and explanatory variables were assessed using random effects logistic regression models for each survey round. Linear, categorical, and non-linear relationships between the set of explanatory variables and parasite prevalence were assessed in separate models for each survey; interaction terms between survey year and ITN coverage, climate, and other covariates were assessed in final pooled models. Final non-spatial model selection was based on the Akaike's Information Criterion (AIC); final spatial model selection was based on the Deviance Information Criterion (DIC). Model fit assessments were conducted in Stata 13.1 [34] and R 3.3.0 [35].

To account for spatial autocorrelation and to produce continuous prediction surfaces for examining spatial patterns in ITN coverage and parasite prevalence, final models were run in a Bayesian geostatistical framework with spatially-correlated random effects (further details in Additional file 1). We compared results of several different geostatistical models including individual, household, and SEA-level parameters to confirm that effect estimates used for final prediction models were not modified by individual level parameters. Additionally, we compared results of geostatistical models with nonspatial random effects models. In a model ('full model') including individual, household, and cluster level parameters we included individual and household-level sociodemographic and vector control parameters (ITNs and IRS), and SEA-level measures of vector control (ITNs and IRS), geography (elevation and Euclidean distance to nearest water body), and climate (rainfall and EVI). In the spatial prediction model ('prediction model') we included only the SEA-level ITN, IRS, geographic, and climate parameters. Additionally, to compare results of varying ITN and IRS coverage and climate inputs on 
predictions, we created separate geostatistical models of ITN coverage, defined as the ratio of ITNs:HH members, and IRS coverage for inclusion in final prediction models. All model parameters were estimated using Integrated Nested Laplace Approximation (INLA) in R [36] (Details in Additional file 1).

\section{Model validation and prediction}

We conducted validation tests on the spatial prediction model and a comparative non-spatial model by calibrating each model on an $85 \%$ training dataset for predicting to the remaining $15 \%$ of locations. The training and prediction datasets were selected through stratified sampling to ensure equal allocation by survey year. We calculated the mean prediction error (MPE) as a measure of bias and the root mean square error (RMSE) as a measure of accuracy. For the final prediction model surfaces, we plotted the posterior mean prediction values for each $5 \mathrm{~km}$ pixel (roughly 40,000 pixels covering Zambia) using INLA in R [36] and ArcGIS [37]. We evaluated several different prediction scenarios by including different combinations of climate and ITN and IRS coverage surfaces for each year as prediction model inputs. For alternative prediction scenarios we focused primarily on changes between 2008 and 2010 as this period was characterized by anomalous climate conditions and the largest changes in measured prevalence. For each prediction scenario we calculated final population-averaged parasite prevalence values per province by multiplying the mean posterior prediction raster by the Worldpop population raster for children $<5$ to obtain the estimated number of infected children $<5$ by province, and then dividing by the total province $<5$ population. To approximate uncertainty in province level estimates, we calculated the population-averaged parasite prevalence for the 2.5 and $97.5 \%$ posterior quantiles.

\section{Results}

The 2006 MIS covered 2,889 households, with slide results available for 1,787 children 1-59 months of age in 109 SEAs (Fig. 1). The 2008 MIS covered 4,142

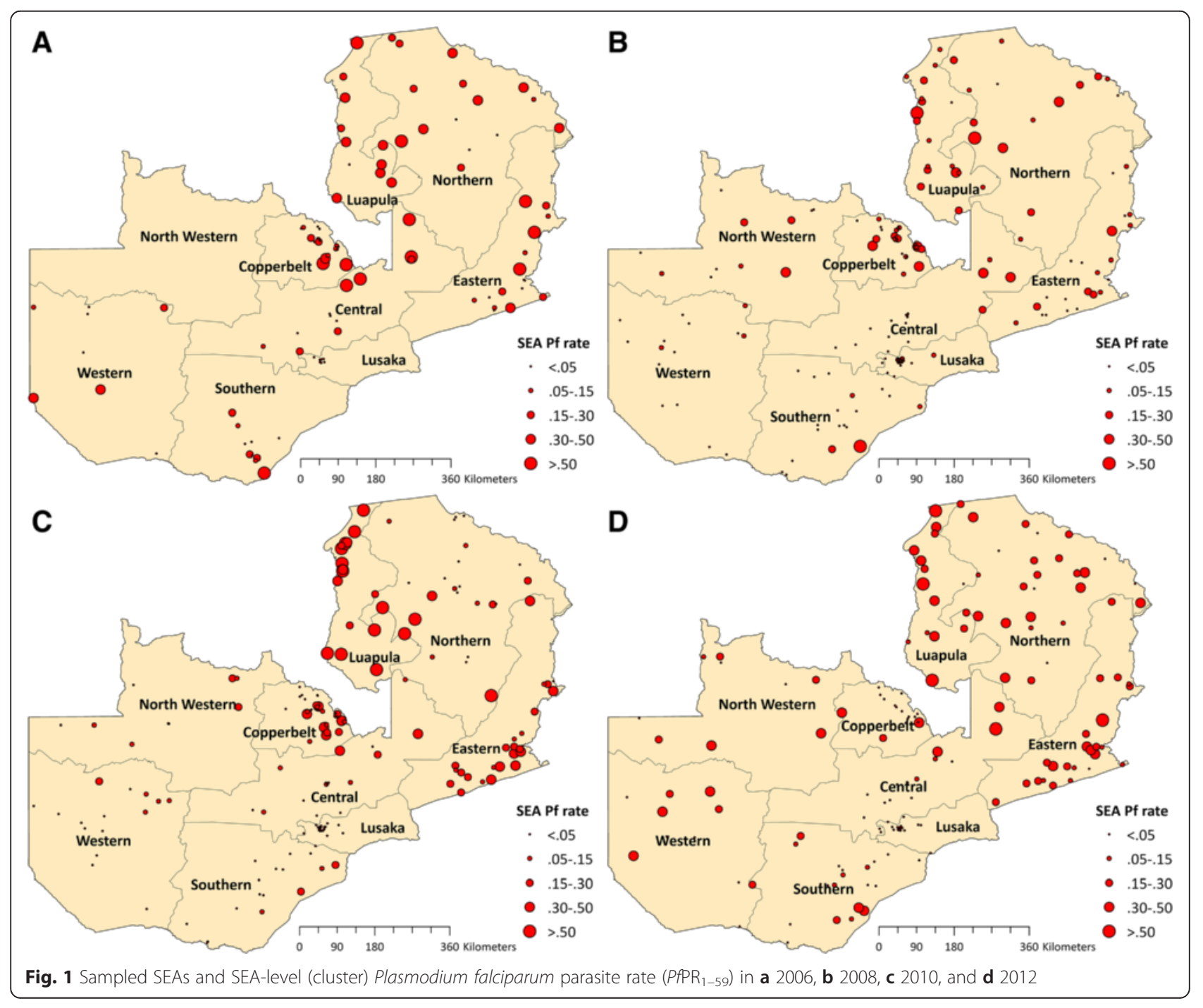


households, with slide results available for 3,010 children in 169 SEAs, while the 2010 MIS covered 4,361 households, with slide results available for 3,423 children in 178 SEAs. The 2012 MIS covered 3,800 households, with slide results available for 2,962 children in 158 SEAs.

Rainfall at survey locations preceding each survey was lowest in 2008 and highest in 2010 across most provinces (Fig. 2); rainfall increased further in 2012 in Copperbelt and Western province. Similarly, temperature suitability preceding each survey was highest in 2010 in most provinces. EVI was highest in 2010 in Luapula, and slightly higher in 2010 than 2008 in Eastern province; EVI increased further in Eastern and Copperbelt provinces in 2012.

While national vector control coverage increased consistently from 2006 to 2008 across Zambia, changes in vector control coverage from 2008 to 2010 varied considerably by province, and differed for ITN and IRS coverage. Between 2008 and 2010, household ownership of $\geq 1$ ITN fell significantly in Luapula (from 69.8 to $50.0 \%, P<0.05$ ) and Northern provinces (from 90.9 to $61.2 \%, P<0.001$ ), while IRS coverage increased significantly in both areas (Table 1); combined, the percent of households with any vector control (ITN and/or IRS) fell significantly in both provinces. In other provinces - Eastern, Copperbelt and Central, household ITN ownership increased slightly. Between 2010 and 2012, the percent of household with an ITN and/or IRS increased substantially in Luapula (from 60.9 to $91.4 \%, P<0.001$ ), Eastern (from 77.8 to $90.4 \%, P<0.05$ ), and Northern (from 66.1 to $78.6 \%, P<0.05$ ), but decreased in Western (from 79.3 to $56.0 \%, P<0.05$ ) and Central (from 77.7 to $65.2 \%, P<0.05$ ).
The ITN-to-population surfaces produced as inputs for spatial prediction showed that this ratio increased overall across provinces from 2006 through 2010, but with substantial spatial heterogeneity, and increased dramatically in 2012 (Additional file 1: Figure S4). The number of ITNs per population increased overall between 2006 to 2008, but most notably in the north and east of the country. Between 2008 and 2010, the number of ITNs per population remained at similar levels in most of the west and south, but fell in the north, most notably in Luapula province. In 2012, this ITN-topopulation ratio was highest in the northeast. IRS coverage was highly focal and higher near urban areas in 2006 and 2008, then increased nationally in 2010 and 2012 (Additional file 1: Figure S5).

While there were consistent declines in measured parasite prevalence across provinces from 2006 to 2008 during the peak transmission seasons in Zambia (national decline of child parasite prevalence from 22.4 \% [95 \% Confidence Interval (CI): $17.6-27.2 \%$ ] to $9.3 \%$ [95 \% CI: 7.0-11.6 \%]), changes in prevalence between 2008 and 2010 at the province level were not uniform. Parasite prevalence increased significantly between 2008 and 2010 nationally (from $9.3 \%$ to $15.9 \%, P<0.001$ ), with quite large increases in Luapula (from 19.6 to $50.5 \%, P<0.001$ ) and Eastern province (from 8.2 to $22.0 \%, P<0.001$ ), and marginally in Northern (from 10.9 to $23.6 \%, P=0.052$ ) (Table 2). Prevalence decreased slightly, but not significantly, in Northwestern (from 14.1 to $6.0 \%, P=0.150$ ) and Southern Province (from 7.7 to $5.7 \%$ ). National prevalence in 2012

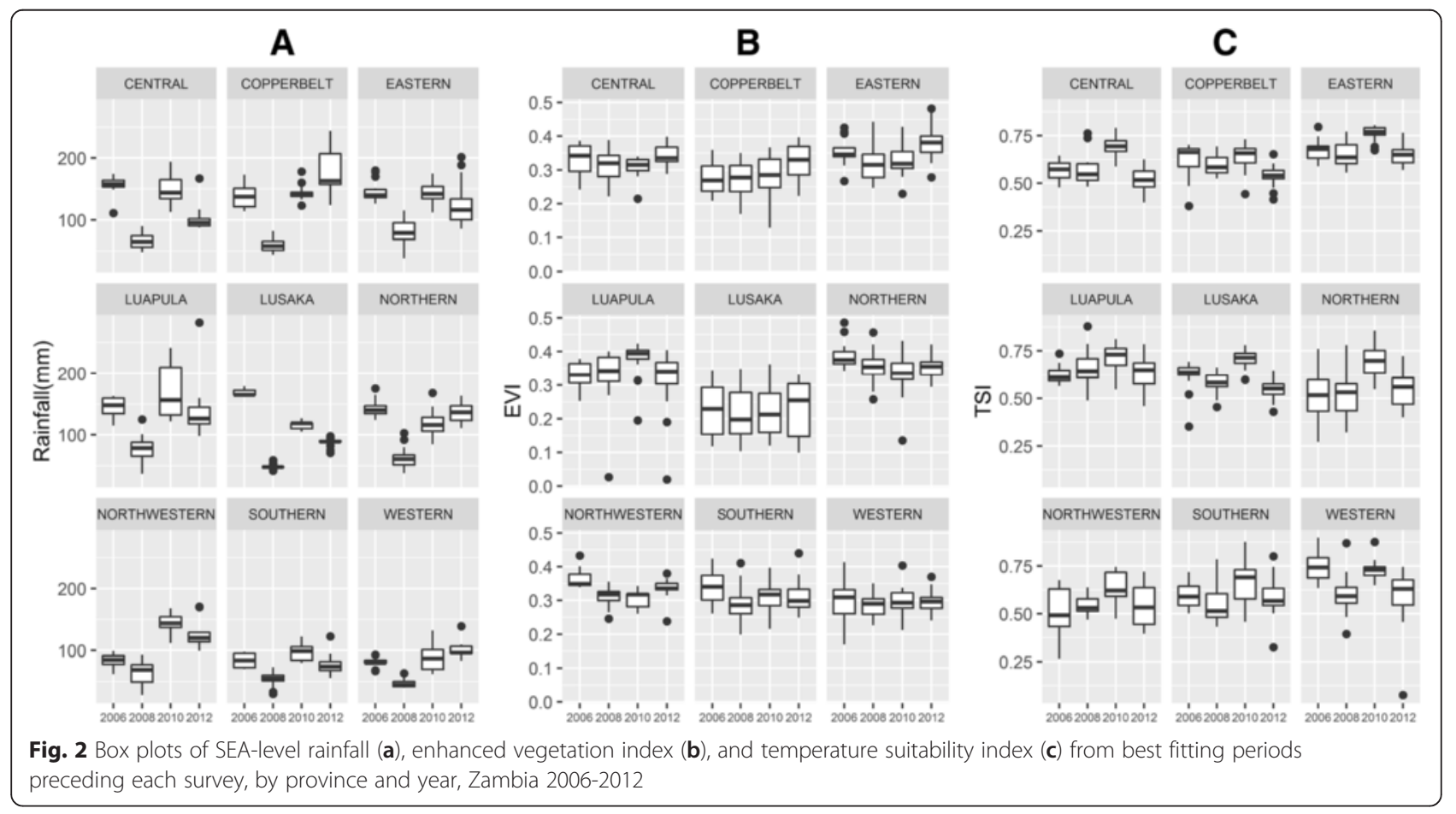


Table 1 Survey measured percent of household owning $\geq 1$ ITN and/or receiving IRS by year and province, Zambia 2006-2010

\begin{tabular}{|c|c|c|c|c|c|c|c|c|c|c|c|c|}
\hline \multirow[b]{2}{*}{ Province } & \multicolumn{3}{|c|}{ ITN ownership (\%) $(95 \%$ Cl) } & \multirow[b]{2}{*}{2012} & \multicolumn{3}{|c|}{ IRS coverage (\%) $(95 \% \mathrm{Cl})$} & \multirow[b]{2}{*}{2012} & \multicolumn{3}{|c|}{ ITN or IRS (\%) $(95 \%$ CI) } & \multirow[b]{2}{*}{2012} \\
\hline & 2006 & 2008 & 2010 & & 2006 & 2008 & 2010 & & 2006 & 2008 & 2010 & \\
\hline Central & $\begin{array}{l}48.4 \\
(38.7-58.1)\end{array}$ & $\begin{array}{l}51.0 \\
(40.2-61.9)\end{array}$ & $\begin{array}{l}74.0 \\
(67.2-80.8)\end{array}$ & $\begin{array}{l}55.7 \\
(47.6-63.5)\end{array}$ & $\begin{array}{l}12.0 \\
(0.0-26.2)\end{array}$ & $\begin{array}{l}19.5 \\
(9.3-29.7)\end{array}$ & $\begin{array}{l}13.0 \\
(4.0-21.9)\end{array}$ & $\begin{array}{l}25.7 \\
(15.2-40.1)\end{array}$ & $\begin{array}{l}55.5 \\
(44.9-66.2)\end{array}$ & $\begin{array}{l}57.2 \\
(45.8-68.6)\end{array}$ & $\begin{array}{l}77.7 \\
(70.9-84.5)\end{array}$ & $\begin{array}{l}65.2 \\
(58.2-71.6)\end{array}$ \\
\hline Lusaka & $\begin{array}{l}26.1 \\
(20.5-31.8)\end{array}$ & $\begin{array}{l}55.4 \\
(48.2-62.6)\end{array}$ & $\begin{array}{l}49.9 \\
(43.2-56.5)\end{array}$ & $\begin{array}{l}55.4 \\
(48.3-62.0)\end{array}$ & $\begin{array}{l}12.2 \\
(4.6-19.8)\end{array}$ & $\begin{array}{l}30.7 \\
(23.3-38.1)\end{array}$ & $\begin{array}{l}34.8 \\
(27.0-42.5)\end{array}$ & $\begin{array}{l}12.3 \\
(8.5-17.4)\end{array}$ & $\begin{array}{l}34.3 \\
(26.8-41.9)\end{array}$ & $\begin{array}{l}66.6 \\
(61.0-72.2)\end{array}$ & $\begin{array}{l}65.2 \\
(59.2-71.2)\end{array}$ & $\begin{array}{l}60.0 \\
(51.5-67.9)\end{array}$ \\
\hline Copperbelt & $\begin{array}{l}30.2 \\
(24.4-35.9)\end{array}$ & $\begin{array}{l}57.2 \\
(51.0-63.5)\end{array}$ & $\begin{array}{l}62.3 \\
(56.3-68.3)\end{array}$ & $\begin{array}{l}62.4 \\
(53.4-70.6)\end{array}$ & $\begin{array}{l}33.9 \\
(19.6-48.2)\end{array}$ & $\begin{array}{l}49.8 \\
(40.2-59.4)\end{array}$ & $\begin{array}{l}46.3 \\
(39.3-53.4)\end{array}$ & $\begin{array}{l}53.5 \\
(46.4-60.4)\end{array}$ & $\begin{array}{l}50.7 \\
(38.2-63.2)\end{array}$ & $\begin{array}{l}75.6 \\
(70.4-80.7)\end{array}$ & $\begin{array}{l}78.1 \\
(73.3-83.0)\end{array}$ & $\begin{array}{l}74.0 \\
(66.0-80.7)\end{array}$ \\
\hline Eastern & $\begin{array}{l}33.5 \\
(22.0-44.9)\end{array}$ & $\begin{array}{l}74.8 \\
(66.3-83.4)\end{array}$ & $\begin{array}{l}76.1 \\
(71.3-81.0)\end{array}$ & $\begin{array}{l}87.6 \\
(80.6-92.4)\end{array}$ & $\begin{array}{l}1.8 \\
(0.1-3.4)\end{array}$ & $\begin{array}{l}0.6 \\
(0.03-1.3)\end{array}$ & $\begin{array}{l}14.0 \\
(4.9-23.1)\end{array}$ & $\begin{array}{l}33.7 \\
(21.1-49.1)\end{array}$ & $\begin{array}{l}34.2 \\
(22.5-45.9)\end{array}$ & $\begin{array}{l}74.8 \\
(66.3-83.4)\end{array}$ & $\begin{array}{l}77.8 \\
(72.5-83.1)\end{array}$ & $\begin{array}{l}90.4 \\
(83.8-94.4)\end{array}$ \\
\hline Luapula & $\begin{array}{l}40.4 \\
(28.7-52.0)\end{array}$ & $\begin{array}{l}69.8 \\
(62.7-76.9)\end{array}$ & $\begin{array}{l}50.0 \\
(43.2-56.5)\end{array}$ & $\begin{array}{l}90.0 \\
(85.6-93.1)\end{array}$ & $\begin{array}{l}0.0 \\
(0.0-1.1)\end{array}$ & $\begin{array}{l}0.3 \\
(0.0-0.7)\end{array}$ & $\begin{array}{l}18.1 \\
(4.9-31.3)\end{array}$ & $\begin{array}{l}16.6 \\
(8.4-30.2)\end{array}$ & $\begin{array}{l}40.4 \\
(28.7-52.0)\end{array}$ & $\begin{array}{l}69.9 \\
(62.9-77.0)\end{array}$ & $\begin{array}{l}60.9 \\
(51.8-70.0)\end{array}$ & $\begin{array}{l}91.4 \\
(87.7-94.0)\end{array}$ \\
\hline Northern & $\begin{array}{l}25.3 \\
(16.6-33.9)\end{array}$ & $\begin{array}{l}90.9 \\
(85.2-96.7)\end{array}$ & $\begin{array}{l}61.2 \\
(52.5-69.9)\end{array}$ & $\begin{array}{l}73.2 \\
(62.6-81.7)\end{array}$ & $\begin{array}{l}2.1 \\
(0.0-5.7)\end{array}$ & $\begin{array}{l}0.5 \\
(0.0-1.3)\end{array}$ & $\begin{array}{l}13.6 \\
(3.1-24.0)\end{array}$ & $\begin{array}{l}20.4 \\
(9.9-37.4)\end{array}$ & $\begin{array}{l}26.0 \\
(17.1-34.9)\end{array}$ & $\begin{array}{l}90.9 \\
(85.2-96.7)\end{array}$ & $\begin{array}{l}66.1 \\
(56.2-76.1)\end{array}$ & $\begin{array}{l}78.6 \\
(71.1-84.5)\end{array}$ \\
\hline $\begin{array}{l}\text { North- } \\
\text { western }\end{array}$ & $\begin{array}{l}42.3 \\
(31.9-52.8)\end{array}$ & $\begin{array}{l}48.4 \\
(25.6-71.2)\end{array}$ & $\begin{array}{l}72.8 \\
(60.8-84.8)\end{array}$ & $\begin{array}{l}77.8 \\
(68.6-84.9)\end{array}$ & $\begin{array}{l}0.5 \\
(0.0-1.4)\end{array}$ & $\begin{array}{l}15.2 \\
(0.0-33.7)\end{array}$ & $\begin{array}{l}7.6 \\
(0.0-17.6)\end{array}$ & $\begin{array}{l}21.6 \\
(7.9-46.9)\end{array}$ & $\begin{array}{l}42.3 \\
(31.9-52.8)\end{array}$ & $\begin{array}{l}60.0 \\
(35.1-85.0)\end{array}$ & $\begin{array}{l}77.4 \\
(70.1-84.7)\end{array}$ & $\begin{array}{l}80.7 \\
(73.9-86.1)\end{array}$ \\
\hline Southern & $\begin{array}{l}46.5 \\
(32.6-60.5)\end{array}$ & $\begin{array}{l}69.9 \\
(60.8-79.0)\end{array}$ & $\begin{array}{l}66.1 \\
(55.4-76.7)\end{array}$ & $\begin{array}{l}63.7 \\
(57.5-69.5)\end{array}$ & $\begin{array}{l}7.1 \\
(0.0-19.6)\end{array}$ & $\begin{array}{l}15.8 \\
(2.8-28.9)\end{array}$ & $\begin{array}{l}23.9 \\
(9.7-38.2)\end{array}$ & $\begin{array}{l}22.8 \\
(12.6-37.7)\end{array}$ & $\begin{array}{l}49.1 \\
(33.1-65.1)\end{array}$ & $\begin{array}{l}75.4 \\
(66.9-83.9)\end{array}$ & $\begin{array}{l}75.6 \\
(64.5-86.6)\end{array}$ & $\begin{array}{l}69.7 \\
(61.7-76.7)\end{array}$ \\
\hline Western & $\begin{array}{l}67.0 \\
(51.1-82.8)\end{array}$ & $\begin{array}{l}33.8 \\
(25.2-42.5)\end{array}$ & $\begin{array}{l}74.7 \\
(65.5-83.9)\end{array}$ & $\begin{array}{l}51.9 \\
(41.7-62.0)\end{array}$ & $\begin{array}{l}1.3 \\
(0.0-3.7)\end{array}$ & $\begin{array}{l}0.0 \\
(0.0-0.8)\end{array}$ & $\begin{array}{l}28.6 \\
(12.4-44.8)\end{array}$ & $\begin{array}{l}12.4 \\
(4.6-29.1)\end{array}$ & $\begin{array}{l}67.0 \\
(51.1-82.8)\end{array}$ & $\begin{array}{l}33.8 \\
(25.2-42.5)\end{array}$ & $\begin{array}{l}79.3 \\
(70.8-87.9)\end{array}$ & $\begin{array}{l}56.0 \\
(46.4-65.2)\end{array}$ \\
\hline National & $\begin{array}{l}37.8 \\
(33.6-42.0)\end{array}$ & $\begin{array}{l}61.0 \\
(56.8-65.2)\end{array}$ & $\begin{array}{l}64.3 \\
(61.2-67.3)\end{array}$ & $\begin{array}{l}68.1 \\
(64.4-71.5)\end{array}$ & $\begin{array}{l}9.6 \\
(5.9-13.3)\end{array}$ & $\begin{array}{l}16.0 \\
(11.8-20.1)\end{array}$ & $\begin{array}{l}24.0 \\
(19.8-28.2)\end{array}$ & $\begin{array}{l}25.9 \\
(21.4-31.0)\end{array}$ & $\begin{array}{l}43.3 \\
(38.6-48.0)\end{array}$ & $\begin{array}{l}67.3 \\
(63.1-71.6)\end{array}$ & $\begin{array}{l}72.9 \\
(70.0-75.7)\end{array}$ & $\begin{array}{l}73.9 \\
(70.5-77.0)\end{array}$ \\
\hline
\end{tabular}

Point estimates and confidence intervals account for survey design 
Table 2 Survey measured parasite prevalence in children 1-59 months. by year and province, Zambia 2006-2012

\begin{tabular}{|c|c|c|c|c|}
\hline \multirow[b]{2}{*}{ Province } & \multicolumn{4}{|c|}{ Parasite prevalence (\%) (95 \% Cl) } \\
\hline & 2006 & 2008 & 2010 & 2012 \\
\hline Central & $31.0(16.0-46.0)$ & $5.6(0.0-11.7)$ & $9.2(2.7-15.7)$ & $8.6(3.4-20.4)$ \\
\hline Lusaka & $0.0(0.0-4.7)$ & $1.2(0.0-2.6)$ & $0.0(0.0-1.0)$ & $0.0(0.0-1.6)$ \\
\hline Copperbelt & $14.3(5.2-23.4)$ & $10.0(4.9-15.0)$ & $12.1(6.0-18.2)$ & $4.6(1.3-15.4)$ \\
\hline Eastern & $23.8(12.1-35.6)$ & $8.2(4.4-12.1)$ & $22.0(17.4-26.6)$ & $20.4(15.6-26.2)$ \\
\hline Luapula & $33.8(23.0-44.5)$ & $19.6(12.5-26.7)$ & $50.5(41.2-59.8)$ & $32.2(22.1-44.4)$ \\
\hline Northern & $30.2(18.9-41.6)$ & $10.9(6.0-15.7)$ & $23.6(9.5-37.7)$ & $22.0(15.7-30.0)$ \\
\hline North-western & $23.4^{\mathrm{a}}$ & $14.1(4.8-23.4)$ & $6.0(0.7-11.4)$ & $16.7(9.6-27.6)$ \\
\hline Southern & $15.5(3.1-27.9)$ & $7.7(0.0-17.0)$ & $5.7(0.4-10.9)$ & $8.5(5.1-13.8)$ \\
\hline Western & $11.2(1.6-20.9)$ & $2.7(0.0-5.9)$ & $5.1(1.2-8.9)$ & $12.6(6.0-24.7)$ \\
\hline National & $22.4(17.6-27.2)$ & $9.3(7.0-11.6)$ & $15.9(12.2-19.6)$ & $14.6(11.9-17.7)$ \\
\hline
\end{tabular}

Point estimates and confidence intervals account for survey design

${ }^{a}$ data missing (prevalence estimated from rapid diagnostic test (RDT) field reports

remained similar to 2010 (14.6 \% [95 \% CI: 11.9-17.7 \%]); compared with 2010 there was a significant decrease in Luapula province (from 50.5 to $32.2 \%, P<0.05$ ) and a nonsignificant decrease in Copperbelt province (from 12.1 to $4.6 \%, P=0.149)$, and slight increases in Northwestern (from 6.0 to $16.7 \%, P=0.063$ ) and Western provinces (from 5.1 to $12.6 \%, P=0.098$ ).

In the full geostatistical model, children in the wealthiest households across the four surveys were less likely to have a parasite infection compared to the poorest (Adjusted odds ratio (AOR): 0.36, 95 \% Bayesian Credible Interval (BCI): 0.24-0.52), as were individuals in areas of higher population density (> 1000/km-sq: $\mathrm{AOR}=0.56,95 \% \mathrm{BCI}$ : $0.35-0.89)$ and at higher altitudes (AOR $=0.19,95 \% \mathrm{BCI}$ : 0.07-0.50) (Table 3), after controlling for climate. Individual household ownership of $\geq 1$ ITN was associated with lower odds of infection (AOR $=0.74,95 \%$ BCI: 0.64-0.86). A higher SEA-level ITN density (ITNs per person) was not associated with malaria parasite infection in the full geostatistical model, but was inversely associated with infection in the prediction model (AOR $=0.42,95 \%$ BCI: 0.18-0.93). Higher SEA-level IRS coverage was significantly protective for child parasite infection (AOR $=0.30,95 \%$ BCI: $0.18-$ 0.51 ). Higher rainfall preceding each survey was positively associated with odds of a parasite infection [standardized to 2 standard deviations (SDs)]: AOR $=2.04$, $95 \%$ BCI $1.38-$ 3.00 ), as was a higher vegetation index (EVI) (standardized to 2 SDs: $\mathrm{AOR}=1.98,95 \% \mathrm{BCI} 1.48-2.65$ ). Further details are presented in Additional file 1.

Spatial prediction models were used to create continuous surfaces for predicted malaria parasite prevalence in children 1-59 months and ITN per person densities. SEA ITN density, SEA IRS coverage, population density, altitude, EVI, rainfall, and distance to nearest water body were used for producing the continuous parasite prevalence surface in 2006, 2008, 2010 and 2012 across Zambia. Out-of-sample
Table 3 Results of geostatistical models predicting malaria parasite prevalence in children 1-59 months, Zambia 2006-2012

\begin{tabular}{|c|c|c|c|c|c|}
\hline \multirow[t]{2}{*}{ Predictor } & & \multicolumn{2}{|c|}{ Full model } & \multicolumn{2}{|c|}{$\begin{array}{l}\text { Prediction } \\
\text { model }\end{array}$} \\
\hline & & $\overline{\mathrm{OR}}$ & $95 \% \mathrm{BCl}$ & $\overline{O R}$ & $95 \% \mathrm{BCl}$ \\
\hline \multirow[t]{5}{*}{ Age in years } & $<1$ (ref) & & & & \\
\hline & $1-2$ & 1.85 & $(1.48-2.32)$ & & \\
\hline & $2-3$ & 3.20 & $(2.57-3.97)$ & & \\
\hline & $3-4$ & 3.14 & $(2.53-3.90)$ & & \\
\hline & $4-5$ & 3.98 & $(3.19-4.95)$ & & \\
\hline \multirow[t]{5}{*}{ Wealth } & Poorest (ref) & & & & \\
\hline & Second & 0.88 & $(0.74-1.04)$ & & \\
\hline & Third & 0.76 & $(0.63-0.91)$ & & \\
\hline & Fourth & 0.62 & $(0.50-0.77)$ & & \\
\hline & Richest & 0.36 & $(0.24-0.52)$ & & \\
\hline \multirow{2}{*}{$\begin{array}{l}\text { Population size } \\
\text { per km-sq }\end{array}$} & $<1000$ & & & & \\
\hline & At least 1000 & 0.56 & $(0.35-0.89)$ & 0.45 & $(0.28-0.72)$ \\
\hline \multirow[t]{2}{*}{ HH ITN ownership } & 0 & & & & \\
\hline & $\geq 1$ & 0.74 & $(0.64-0.86)$ & & \\
\hline $\begin{array}{l}\text { Cluster ITN per } \\
\text { person }\end{array}$ & & 0.62 & $(0.27-1.37)$ & 0.42 & $(0.18-0.93)$ \\
\hline Cluster IRS rate & & 0.30 & $(0.18-0.51)$ & 0.25 & $(0.15-0.43)$ \\
\hline $\begin{array}{l}\text { Distance to nearest } \\
\text { water }(\mathrm{km})\end{array}$ & & 0.98 & $(0.95-1.02)$ & 0.98 & $(0.94-1.02)$ \\
\hline Altitude (km) & & 0.19 & $(0.07-0.50)$ & 0.17 & $(0.07-0.45)$ \\
\hline $\begin{array}{l}\text { Enhanced Vegetation } \\
\text { Index }\end{array}$ & $\left(2 \mathrm{SDs}^{\mathrm{a}}\right)$ & 1.98 & $(1.48-2.65)$ & 2.09 & $(1.55-2.81)$ \\
\hline Rainfall (mm) & (2 SDs) & 2.04 & $(1.38-3.00)$ & 2.03 & $(1.38-2.97)$ \\
\hline Spatial variance & & 1.81 & $(1.35-2.39)$ & 1.78 & $(1.33-2.35)$ \\
\hline
\end{tabular}

Odds ratio (OR) and $95 \%$ Bayesian Credibility Interval $(\mathrm{BCl})$ presented where relevant

${ }^{\mathrm{a}} S D$ standard deviation 
validation of this spatial prediction model indicated decent model fit: the overall MPE was only -0.0125 , indicating low bias, and the RMSE was 0.139 , indicating decent accuracy.

Parasite prevalence risk surfaces show the highest risk in 2006 in Luapula, Northern, and Eastern provinces, and reduced risk across provinces in 2008 (Fig. 3). In 2010, resurgence of parasite prevalence was most notable in Luapula province and portions of Eastern province. From these predicted surfaces, population-adjusted parasite prevalence estimates were similar to the MIS estimates, with national and provincial level changes by survey year consistent with changes estimated by MIS tabulations (Table 4). Table 4 and Fig. 4 present alternative scenarios of climate and ITN coverage based upon altering prediction inputs.

The model predicted an increase from 10.4 to $15.3 \%$ (a $47 \%$ relative increase) in national population-adjusted parasite prevalence (PAPfPR $1-59$ ) between 2008 and 2010 across Zambia. Estimates of the expected prevalence if climate were constant between 2008 and 2010 indicated that the bulk of the change between 2008 and 2010 was due to climate factors. Based on spatial model predictions we estimated that a slight relative decrease $(5 \%)$ in parasite prevalence would have occurred between 2008 and 2010 if climate and environmental influences (rainfall and EVI) had remained at 2008 levels. Decreases in PAPfPR ${ }_{1-59}$ between 2008 and 2010 were predicted for most provinces in this scenario, the exceptions being predicted increases, from 19.9 to $27.5 \%$, in Luapula, and from 12.5 to $17.7 \%$ in Eastern province. Alternatively, holding ITN and IRS levels constant from 2008 to 2010 resulted in a predicted relative increase from 10.4 to $15.7 \%$ (a $51 \%$ relative increase) in parasite prevalence nationally based on climate alone, with the largest increases under this scenario in Luapula (from
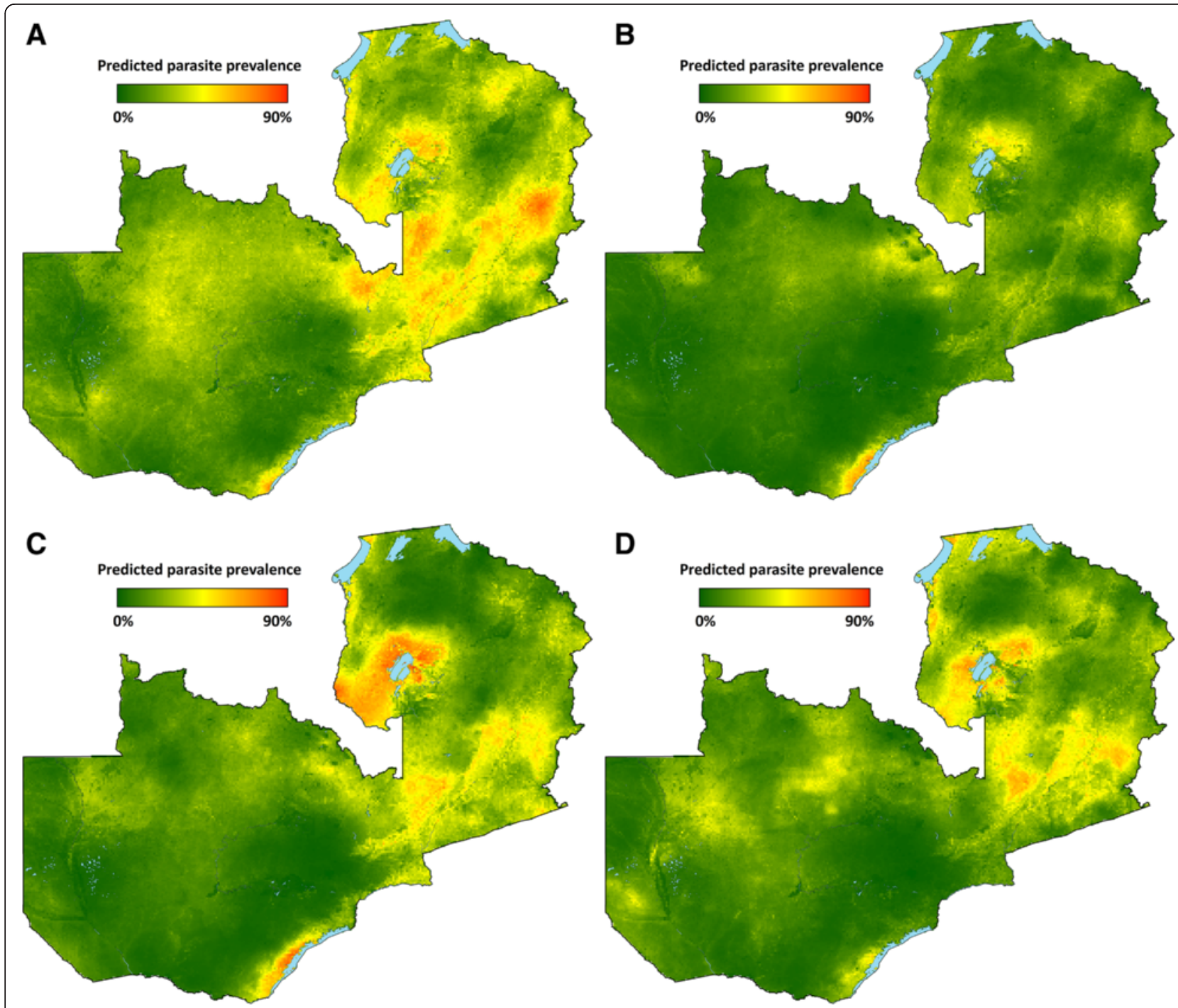

Fig. 3 Predicted mean PfPR $1-59$ surfaces for spatial prediction model in a 2006, b 2008, c 2010, and d 2012 
Table 4 Modeled population-adjusted predicted prevalence (PAPfPR $1-59$ ) by province and year, and predictions under constant climate or ITN scenarios, Zambia 2006-2012. Alternative predictions for 2010 were produced by including either the 2008 climate layers (for constant climate prediction) or the 2008 ITN and IRS layers (for constant vector control prediction)

\begin{tabular}{|c|c|c|c|c|c|c|}
\hline \multirow[b]{2}{*}{ Province } & \multicolumn{4}{|c|}{ Annual predictions (\%) (95 \% BCl) } & \multicolumn{2}{|c|}{ Alternative predictions for 2010 (\%) (95\% BCl) } \\
\hline & 2006 & 2008 & 2010 & 2012 & With constant climate & With constant vector control \\
\hline Central & $22.7(5.0-52.4)$ & $8.8(1.3-27.1)$ & $15.0(3.2-36.4)$ & $12.9(2.7-33.2)$ & $7.8(1.3-23.4)$ & $15.8(3.4-37.6)$ \\
\hline Lusaka & $5.4(0.7-16.5)$ & $1.8(0.2-5.8)$ & $1.7(0.2-5.4)$ & $1.0(0.1-3.7)$ & $0.7(0.1-2.7)$ & $1.9(0.2-5.7)$ \\
\hline Copperbelt & $17.3(5.1-38.4)$ & $14.8(5.9-29.0)$ & $13.2(5.5-26.0)$ & $6.0(1.2-16.5)$ & $7.1(2.7-15.3)$ & $12.8(5.2-25.1)$ \\
\hline Eastern & $29.9(8.6-60.0)$ & $12.5(3.2-30.7)$ & $28.0(10.1-54.1)$ & $23.0(7.7-47.4)$ & $17.7(5.4-39.3)$ & $29.6(10.9-56.1)$ \\
\hline Luapula & $31.6(9.7-63.2)$ & $19.9(5.8-43.7)$ & $35.1(14.5-60.8)$ & $32.8(12.4-59.3)$ & $27.5(9.8-52.9)$ & $35.4(14.6-61.5)$ \\
\hline Northern & $26.8(6.5-60.1)$ & $14.4(3.1-39.4)$ & $17.3(5.2-39.7)$ & $19.7(5.6-44.9)$ & $12.3(3.3-30.6)$ & $17.0(5.1-39.1)$ \\
\hline North-western & $22.3(2.2-65.3)$ & $12.7(1.6-40.7)$ & $16.0(2.2-48.8)$ & $17.6(2.9-49.9)$ & $9.6(1.2-33.0)$ & $17.1(2.4-50.8)$ \\
\hline Southern & $11.4(1.7-36.5)$ & $7.1(1.7-18.8)$ & $9.6(2.3-24.1)$ & $7.7(1.7-21.9)$ & $6.1(1.1-17.3)$ & $9.5(2.3-23.4)$ \\
\hline Western & $16.1(2.2-47.3)$ & $5.8(0.6-22.1)$ & $8.1(1.0-27.9)$ & $14.3(2.3-42.1)$ & $5.3(0.6-19.8)$ & $9.7(1.3-31.9)$ \\
\hline National & $19.6(4.6-46.4)$ & $10.4(2.6-26.8)$ & $15.3(4.9-33.7)$ & $13.5(3.7-31.7)$ & $9.9(2.7-24.2)$ & $15.7(5.0-34.3)$ \\
\hline
\end{tabular}

19.9 to $35.4 \%$ ), Eastern (from 12.5 to $29.6 \%$ ) and Central (from 8.8 to $15.8 \%$ ) provinces.

\section{Discussion}

We used a geostatistical model to assess the subnational associations between population-based measures of vector control coverage, inter-annual climate variability, and parasite prevalence in Zambia in 2006, 2008, 2010, and 2012 from the MIS in these years. In doing so, we were able to isolate the contributing effects of changes in ITN and IRS coverage and climate on changes in parasite prevalence at the subnational level in Zambia over this period, with a specific focus on changes that occurred between 2008 and 2010.
Rainfall, temperature suitability, and vegetation indices were all higher in 2006, 2010, and 2012, as compared with 2008. The measured malaria parasite prevalence across Zambia decreased from $22.4 \%$ in 2006 to $9.3 \%$ in 2008, then increased to $15.9 \%$ in 2010 and $14.6 \%$ in 2012. These changes in parasite prevalence were not uniform across the entire country and were mostly concentrated in specific provinces. Accounting for climate variations between 2006 and 2012 within a geostatistical framework, we show that the increase in parasite prevalence observed in several provinces between 2008 and 2010 corresponded both with decreases in household ITN coverage and with warmer and wetter conditions influencing the potential for underlying malaria transmission intensity, with a greater contribution
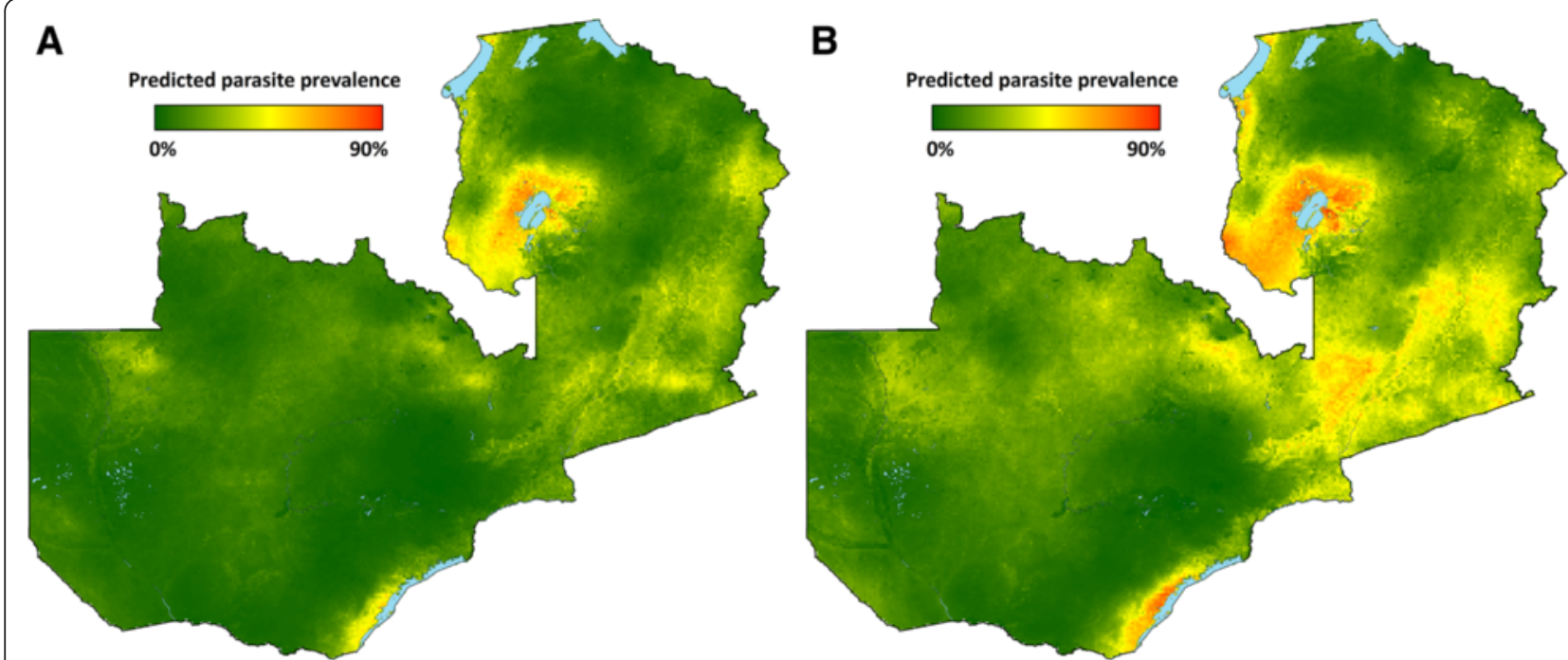

Fig. 4 Predicted mean PfPR $1-59$ surfaces for spatial prediction model under alternative prediction scenarios: a 2010 ITN/IRS, 2008 climate; b 2010 climate, 2008 ITN/IRS 
due to climate variability. In geostatistical prediction models, we estimated that while the national increase in populationadjusted predicted parasite prevalence between 2008 and 2010 was from 10.4 to $15.3 \%$ (a relative increase of $47 \%$ ), prevalence would have risen to $15.7 \%$ (a relative increase of $51 \%$ ) if vector control was the same as in 2008. We estimate that while population-adjusted parasite prevalence increased relatively by almost $80 \%$ from 2008 to 2010 in Luapula, prevalence would have increased by close to $40 \%$ relatively due to lower ITN coverage alone. However, given the wide uncertainty in predicted prevalences, the credibility intervals for predictions overlapped, which limits our ability to make statistical conclusions about these results.

Although heterogeneity in ITN coverage over this period played a substantial role as ITN coverage fell in several of the provinces that experienced the greatest increase, these patterns do not completely explain the observed rebound. Higher community ITN density (ITNs per individual) and higher IRS household coverage were each significantly associated with reduced odds of parasite infection across all surveys, and coverage of each of these fell significantly in Northern and Luapula province between 2008 and 2010. Provinces where community vector control coverage in 2010 was at least as high in 2008 did not experience significant increases in infection prevalence, with the exception of Eastern province. In 2012, ITN coverage reached very high levels in Luapula and Eastern, but while prevalence dropped from 2010, it remained high. In Western province, ITN coverage fell in 2012, and this was associated with a more than doubling in parasite prevalence.

While IRS rates increased, the proportion of households with a newer ITN ( $<2$ years old) decreased dramatically in Northern, Luapula, and Eastern province between 2008 and 2010. This was likely the result of the staggered LLIN distribution campaigns that resulted in some provinces not receiving new nets until after 2010 . This highlights the need for programs to work diligently at ensuring vector control coverage does not lapse in certain areas due to issues with net redistribution or spray efforts.

Climatic factors influencing malaria transmission, including rainfall, temperature suitability, and vegetation cover (EVI), were positively associated with malaria parasite prevalence in children across space and time. Overall, in Zambia, 2010 was wetter and hotter as compared to 2006 and 2008, with 2008 the driest and coolest of the time periods preceding each survey. This increase in rainfall and surface moisture in 2010 as compared to 2008 was most pronounced in areas experiencing the greatest increases in malaria parasite prevalence over this time period. Conditions in 2012 were similar to 2006, reinforcing that patterns in 2008 and 2010 were somewhat anomalous.
These changes in rainfall and temperature patterns may reflect regional effects of the El Niño Southern Oscillation (ENSO), as early 2010 was characterized by a moderately strong El Niño event, and early 2008 by a moderate $L a$ Niña event. However, the effects of the ENSO on the southern Africa region are varied, and likely dependent upon latitude [38]. Previous research found that La Niña years predict higher incidence in Botswana, which is similar ecologically to parts of southern Zambia [18]. Conversely, El Niño years have historically affected the northern part of the region [38]. This pattern may partially explain the rebound in the provinces in the northern part of country. Evidence of the influence of climate conditions favorable for malaria transmission in 2010 in southern Africa was not limited to Zambia. Similar trends were observed in subnational surveys in Malawi between 2005 and 2010 (PMI Malawi Impact Evaluation, personal communication). An increase in parasite prevalence in other countries in central Africa (e.g. Rwanda) may have also been influenced by a combination of intervention fall-back and climate factors. Trends in health facility data in Zambia and Malawi also coincide with a resurgence in malaria that began in 2009 and increased through 2010 [39].

Climate and ITN variables do not completely explain observed subnational changes in malaria parasite prevalence between 2008 and 2010. Immunological factors and other transmission dynamics between survey years may have influenced prevalence in ways not fully captured in geostatistical models. For example, older children in 2010 would have likely been less exposed to infectious mosquitoes in 2008 following the ITN distribution and a drier late-transmission season, and therefore possibly have weaker acquired immunity in 2010 than similarly aged children would have in 2008. They might therefore have been less able to clear infections or suppress parasite densities [40-42]. Other factors that must be considered in the resurgence in 2010 in some areas include ACT drug shortages and insecticide resistance. However, reported ACT levels were largely consistent between 2006 and 2010, and treatment seeking and treatment of fevers with an ACT has increased since 2006 [43]. Additionally, prevalence remained high in 2012, even as ACT coverage increased. As a result, these factors were not likely to have played a substantial role in increased prevalence over this period. Insecticide resistance may have contributed, but its role on a national scale is largely unknown, as studies have been very localized [10-12]. Mathematical modeling has furthermore suggested that the duration of the effects of LLIN provision may vary with transmission setting, such that the effective lifetime is shortened in higher transmission settings [44]. However, in our study ITNs at the community level and IRS at the household level were shown to be protective against malaria parasite infections across 
survey years, with no statistical evidence of ITN effectiveness decay as assessed by interaction terms between survey year and both household ITN ownership and community ITN density (non-significant interactions).

As with any cross-sectional study, this analysis was limited in its ability to adequately examine longitudinal trends. The utilization of repeated cross-sectional surveys allows only for examinations of contemporaneous association with limited causal inference [45]. Given that control with ITNs and IRS has been scaled-up nationwide, we lacked a true control group that would allow us to make stronger counterfactual arguments. We attempted to mitigate some of these limitations through the use of matching based upon residence status in non-spatial models and found associations similar to those in geostatistical models. Similarly, we approximated province level uncertainty in predictions by using the 2.5 and $97.5 \%$ posterior quantiles at the pixel level. Given the known computational difficulties with producing aggregate-level uncertainty from geostatistical surfaces [46], we were not able in this study to incorporate the full pixel-level covariances. Additionally, further work is needed to parameterize potentially nonlinear relationships between ITN coverage and parasite prevalence in a geostatistical framework.

The use of lagged climate variables to predict prevalence is confounded by the length of a malaria infection, which averages over 200 days without treatment [47]. However, as diagnostic and treatment capacity increased dramatically over this period, prevalence would have likely tracked incidence more closely as infections were cleared with more rapid effective treatment. Similarly, as transmission drops, as it did between 2006 and 2008, some children may lose acquired immunity, and therefore present with more symptomatic disease necessitating treatment. These effects would seem to bias toward shorter infections, which could potentially allow for more accurate estimation of climatic time lags with prevalence data. A strong relationship between climate and prevalence through time is supported by recent analyses of community-level surveillance data in Eastern province showing that the seasonality in prevalence closely tracks incidence [48].

\section{Conclusions}

There is increasing effort to conduct repeated national surveys to generate data for malaria program evaluations. Without carefully considering and explicitly modeling confounding factors, especially climate, results of these surveys may lead to spurious conclusions of program effect or lack thereof, especially when assessing changes at the national level. In Zambia, it was surmised that ITNs began to fail after 2008 and contributed to increases in national infection prevalence by 2010 . However, once one explicitly models changes in inter-annual climate variability at the subnational level, in conjunction with changes in
ITN population coverage at the subnational level, we show that without the ITN coverage already in place in 2010, the malaria burden as measured by predicted parasite prevalence would have been worse in 2010 than actually observed. In doing so, this analysis represents a novel approach to applying geostatistical methods for malaria program evaluation. These results are important as malaria control programs attempt to interpret changes in prevalence and attribute them to program effort, or lack thereof, in the context of inter-annual climate variability. Subnational changes in malaria parasite prevalence are highly influenced by climate over short time scales and must be accounted for in assessing the effectiveness of malaria control programs.

\section{Additional file}

Additional file 1: Supplementary information: Additional modeling results and maps of vector control coverage. (DOCX $1 \mathrm{mb}$ )

\section{Acknowledgements}

The authors would like to acknowledge the field teams who collected these data, as well as the communities who participated.

\section{Funding}

$A B$ and TPE were funded through a subcontract from PATH-MACEPA PATH-MACEPA was funded by the Bill and Melinda Gates Foundation (BMGF). BMGF had no role in the design of the study, the collection, analysis, and interpretation of data, or writing of the manuscript and the decision to publish.

\section{Availability of data and materials}

All data are the property of the Zambia National Malaria Control Centre and can be shared with their permission.

\section{Authors' contributions}

$A B$ developed the research question, performed the statistical analyses, interpreted the results and drafted the manuscript. JY assisted with statistical analyses and development of the analysis plan and edited the manuscript draft. JM led MIS survey study design, coordinated data collection efforts and edited the manuscript draft. JK assisted with development of the analysis plan and edited the manuscript draft. HM co-ordinated laboratory analyses. BH and MK supported data collection and MIS survey study design. PV and RAP advised on statistical analyses. RS provided intellectual content and edited the manuscript draft.

TPE supervised development of the analysis plan and manuscript drafting and editing. All authors read and approved the final manuscript.

\section{Competing interests}

The authors declare that they have no competing interests.

\section{Ethics approval and consent to participate}

Informed consent was provided by all survey participants (or their guardian) before questionnaire administration and malaria testing. Further, all survey protocols were approved by the Internal Review Boards of PATH, University of Zambia, and Tulane University.

\section{Author details}

${ }^{1}$ Malaria Elimination Initiative, Global Health Group, University of California, 500 16th St, San Francisco, CA 94158, USA. ${ }^{2}$ Center for Applied Malaria Research and Evaluation, Tulane University School of Public Health and Tropical Medicine, New Orleans, LA, USA. ${ }^{3}$ PATH Malaria Control and Evaluation Partnership in Africa (MACEPA), Lusaka, Zambia. ${ }^{4}$ National Malaria Control Centre, Ministry of Health, Lusaka, Zambia. ${ }^{5}$ Swiss Tropical and Public Health Institute, Basel, Switzerland. ${ }^{6}$ University of Basel, Basel, Switzerland. 
Received: 7 January 2015 Accepted: 11 July 2016

\section{Published online: 05 August 2016}

\section{References}

1. Lim SS, Fullman N, Stokes A, Ravishankar N, Masiye F, Murray CJ, et al. Net benefits: a multicountry analysis of observational data examining associations between insecticide-treated mosquito nets and health outcomes. PLOS Med. 2011;8(9):e1001091.

2. Lengeler $C$. Insecticide-treated bed nets and curtains for preventing malaria. The Cochrane database of systematic reviews. 2004;2:CD000363.

3. ter Kuile FO, Terlouw DJ, Phillips-Howard PA, Hawley WA, Friedman JF, Kolczak MS, et al. Impact of permethrin-treated bed nets on malaria and all-cause morbidity in young children in an area of intense perennial malaria transmission in western Kenya: cross-sectional survey. AmJTrop Med Hyg. 2003;68(4 Suppl):100-7.

4. Pluess B, Tanser FC, Lengeler C, Sharp BL. Indoor residual spraying for preventing malaria. The Cochrane database of systematic reviews. 2010;4:CD006657.

5. Bhatt S, Weiss DJ, Cameron E, Bisanzio D, Mappin B, Dalrymple U, et al. The effect of malaria control on Plasmodium falciparum in Africa between 2000 and 2015. Nature. 2015;526(7572):207-11.

6. Steketee RW, Sipilanyambe N, Chimumbwa J, Banda JJ, Mohamed A, Miller J, et al. National malaria control and scaling up for impact: the Zambia experience through 2006. AmJTrop Med Hyg. 2008;79(1):45-52.

7. Chizema-Kawesha E, Miller JM, Steketee RW, Mukonka VM, Mukuka C, Mohamed AD, et al. Scaling up malaria control in Zambia: progress and impact 2005-2008. Am J Trop Med Hyg. 2010;83(3):480-8.

8. Chizema-Kawesha E, Miller JM, Steketee RW, Mukonka VM, Mukuka C, Mohamed AD, et al. Scaling up malaria control in Zambia: progress and impact 2005-2008. AmJTrop Med Hyg. 2010;83(3):480-8.

9. Cohen JM, Smith DL, Cotter C, Ward A, Yamey G, Sabot OJ, et al. Malaria resurgence: a systematic review and assessment of its causes. Malar J. 2012;11:122.

10. Trape JF, Tall A, Diagne N, Ndiath O, Ly AB, Faye J, et al. Malaria morbidity and pyrethroid resistance after the introduction of insecticide-treated bednets and artemisinin-based combination therapies: a longitudinal study. Lancet Infect Dis. 2011;11(12):925-32.

11. Wondji CS, Coleman M, Kleinschmidt I, Mzilahowa T, Irving H, Ndula M, et al. Impact of pyrethroid resistance on operational malaria control in Malawi. Proc Natl Acad Sci U S A. 2012;109:19063-70.

12. Moiroux N, Gomez MB, Pennetier C, Elanga E, Djenontin A, Chandre F, et al. Changes in Anopheles funestus biting behavior following universal coverage of long-lasting insecticidal nets in Benin. J Infect Dis. 2012;206(10):1622-9.

13. Mabaso ML, Kleinschmidt I, Sharp B, Smith T. El Nino Southern Oscillation (ENSO) and annual malaria incidence in Southern Africa. Trans R Soc Trop Med Hyg. 2007;101(4):326-30

14. Jones AE, Wort UU, Morse AP, Hastings IM, Gagnon AS. Climate prediction of El Nino malaria epidemics in north-west Tanzania. Malar J. 2007;6:162.

15. Teklehaimanot HD, Lipsitch M, Teklehaimanot A, Schwartz J. Weather-based prediction of Plasmodium falciparum malaria in epidemic-prone regions of Ethiopia I. Patterns of lagged weather effects reflect biological mechanisms. Malar J. 2004:3:41.

16. Hay SI, Guerra CA, Gething PW, Patil AP, Tatem AJ, Noor AM, et al. A world malaria map: Plasmodium falciparum endemicity in 2007. PLOS Med. 2009;6(3), e1000048.

17. Samadoulougou S, Maheu-Giroux M, Kirakoya-Samadoulougou F, De Keukeleire M, Castro MC, Robert A. Multilevel and geo-statistical modeling of malaria risk in children of Burkina Faso. Parasites Vectors. 2014;7:350.

18. Thomson MC, Mason SJ, Phindela T, Connor SJ. Use of rainfall and sea surface temperature monitoring for malaria early warning in Botswana. AmJTrop Med Hyg. 2005;73(1):214-21.

19. Bennett A, Kazembe L, Mathanga DP, Kinyoki D, Ali D, Snow RW, et al. Mapping malaria transmission intensity in Malawi, 2000-2010. AmJTrop Med Hyg. 2013;89(5):840-9.

20. Noor AM, Kinyoki DK, Mundia CW, Kabaria CW, Mutua JW, Alegana VA, et al. The changing risk of Plasmodium falciparum malaria infection in Africa: 2000-10: a spatial and temporal analysis of transmission intensity. Lancet. 2014;383(9930):1739-47.

21. Graves PM, Osgood DE, Thomson MC, Sereke K, Araia A, Zerom M, et al. Effectiveness of malaria control during changing climate conditions in Eritrea, 1998-2003. Trop Med Int Health. 2008;13(2):218-28.
22. Over M, Bakote'e B, Velayudhan R, Wilikai P, Graves PM. Impregnated nets or ddt residual spraying? Field effectiveness of malaria prevention techniques in solomon islands, 1993-1999. AmJTrop Med Hyg. 2004;71(2 Suppl):214-23.

23. Bennett A, Yukich J, Miller JM, Vounatsou P, Hamainza B, Ingwe M, et al. A methodological framework for the improved use of routine health system data to evaluate national malaria control programs: evidence from Zambia. Population Health Metrics. 2014;12(1):30.

24. Giardina F, Kasasa S, Sie A, Utzinger J, Tanner M, Vounatsou P. Effects of vector-control interventions on changes in risk of malaria parasitaemia in sub-Saharan Africa: a spatial and temporal analysis. Lancet Global Health. 2014:2(10):e601-15.

25. MEASURE. Demographic and Health Surveys (DHS). Available from: http:// www.measuredhs.com/.

26. USGS. Famine Early Warning System Network. Available from: http:// earlywarning.usgs.gov/fews/. [Accessed Mar 2016].

27. USGS. Hydro 1k. Available from: http://eros.usgs.gov/\#/Find_Data/Products_ and_Data_Available/HYDRO1K. [Accessed Nov 2015].

28. USGS/NASA. The Moderate Resolution Imaging Spectroradiometer (MODIS). Available from: https://pdaac.usgs.gov/dataset_discovery/modis/modis_ products_table. [Accessed March 2016].

29. Weiss DJ, Bhatt S, Mappin B, Van Boeckel TP, Smith DL, Hay SI, et al. Air temperature suitability for Plasmodium falciparum malaria transmission in Africa 2000-2012: a high-resolution spatiotemporal prediction. Malar J. 2014;13:171.

30. Worldpop. Available from: http://www.worldpop.org.uk/. [Accessed March 2016].

31. Roll Back Malaria Partnership (RBM). Monitoring and Evaluation Reference Group (MERG). Available from: http://www.rollbackmalaria.org/architecture/ working-groups/merg.

32. Rutstein SO, Johnson K. The DHS Wealth Index. DHS Comparative Reports No. 6. Calverton: ORC Macro; 2004.

33. Hay SI, Guerra CA, Tatem AJ, Atkinson PM, Snow RW. Urbanization, malaria transmission and disease burden in Africa. Nat Rev Microbiol. 2005;3(1):81-90

34. tataCorp. Stata Statistical Software: Release 13. College Station: StataCorp LP; 2013

35. Team RC. R: A language and environment for statistical computing. Vienna: R Foundation for Statistical Computing; 2013.

36. R-INLA: INLA; Available from: www.r-inla.org. [Accessed March 2016].

37. ESRI. ArcGIS Desktop: Release 10.2.2. Redlands: Environmental Systems Research; 2014.

38. Ogalla L. Validity of the ENSO-related impacts in eastern and southern Africa. Nairobi: UNEP. 1994

39. WHO. World Malaria Report 2013. 2013.

40. Okiro EA, Al-Taiar A, Reyburn H, Idro R, Berkley JA, Snow RW. Age patterns of severe paediatric malaria and their relationship to Plasmodium falciparum transmission intensity. Malar J. 2009:8:4.

41. O'Meara WP, Mwangi TW, Williams TN, McKenzie FE, Snow RW, Marsh K. Relationship between exposure, clinical malaria, and age in an area of changing transmission intensity. AmJTrop Med Hyg. 2008;79(2):185-91.

42. O'Meara WP, Bejon P, Mwangi TW, Okiro EA, Peshu N, Snow RW, et al. Effect of a fall in malaria transmission on morbidity and mortality in Kilifi, Kenya. Lancet. 2008;372(9649):1555-62.

43. National Malaria Control Centre, Ministry of Health, Zambia. Available from: http://www.nmcc.org.zm/. [Accessed March 2016].

44. Briet OJ, Hardy D, Smith TA. Importance of factors determining the effective lifetime of a mass, long-lasting, insecticidal net distribution: a sensitivity analysis. Malar J. 2012;11:20.

45. Rowe AK, Steketee RW, Arnold F, Wardlaw T, Basu S, Bakyaita N, et al. Viewpoint: evaluating the impact of malaria control efforts on mortality in sub-Saharan Africa. Trop Med Int Health. 2007;12(12):1524-39.

46. Gething PW, Patil AP, Hay SI. Quantifying aggregated uncertainty in Plasmodium falciparum malaria prevalence and populations at risk via efficient space-time geostatistical joint simulation. PLoS Comput Biol. 2010;6(4), e1000724.

47. Felger I, Maire M, Bretscher MT, Falk N, Tiaden A, Sama W, et al. The dynamics of natural Plasmodium falciparum infections. PLoS One. 2012;7(9), e45542.

48. Hamainza B, Moonga H, Sikaala CH, Kamuliwo M, Bennett A, Eisele TP, et al. Monitoring, characterization and control of chronic, symptomatic malaria infections in rural Zambia through monthly household visits by paid community health workers. Malar J. 2014;13:128. 